\title{
Plasma insulin response to oral carbohydrate in patients with glucose and lactose malabsorption
}

\author{
J. D. MAXWELL ${ }^{1}$, MARGARET T. McKIDDIE, ANNE FERGUSON, AND \\ K. D. BUCHANAN \\ From the University Department of Medicine, Royal Infirmary, Glasgow
}

SUMMARY Plasma insulin levels were determined following oral glucose in 12 patients with adult coeliac disease, after oral lactose in four patients with alactasia, and in age-matched control subjects.

In coeliac patients the insulin response was greater than expected from the small rise in blood sugar, and no correlation was found between plasma insulin and sugar levels at any period during the test. The separation of the plasma insulin curve from the blood sugar curve after glucose is in keeping with the concept that a factor responsible for stimulating insulin secretion is released from the gut during or after absorption of glucose.

In patients with selective lactose malabsorption (alactasia) administration of lactose by mouth failed to elicit any insulin response, indicating that the insulin-releasing effect of the bowel is not activated merely by the presence of intraluminal carbohydrate.

The availability of a sensitive immunoassay has led to the recognition that the secretion of insulin in vivo is closely dependent on the blood sugar level (Yalow and Berson, 1960) and studies with isolated pancreas preparations have shown a similar increase in insulin output when the glucose concentration in the incubating medium is raised (Malaisse, Malaisse-Lagae, and Wright, 1967).

Increase in blood glucose above a threshold level was considered to be the only important physiological stimulus for insulin release (Field, 1964) until the demonstration by McIntyre, Holdsworth, and Turner (1964) that the infusion of glucose into the jejunum produced a greater rise in insulin than an equivalent amount infused intravenously indicated that factors other than the blood glucose level were concerned in the insulin response following oral glucose.

Absorption of glucose may release a humoral substance from the bowel which then acts, together with the increase in blood glucose, in

Received for publication 6 April 1970.

'Present address: Department of Medicine, King's College Hospital, London SE5. stimulating release of insulin from islet cells (McIntyre et al, 1964). An insulinotropic effect has been attributed to various gastrointestinal hormones (see the reviews by Holdsworth, 1969, and Mayhew, Wright, and Ashmore, 1969) but the mechanisms involved in gut-mediated insulin release are not clearly understood. We have approached this problem by studying the plasma insulin response to oral glucose in patients with adult coeliac disease (with subtotal villous atrophy and malabsorption of glucose) and to the disaccharide lactose in patients with selective lactose malabsorption (alactasia).

\section{Patients and Methods}

COELIAC DISEASE

Twelve patients (five male and seven female), with a mean age of 42 years, who weighed on average $10 \%$ less than ideal for height and sex, were studied. Four patients had started a gluten- 
free diet, while the remaining eight were studied before gluten withdrawal. Jejunal biopsy at the time of study showed subtotal atrophy in all patients.

Standard $50 \mathrm{~g}$ oral glucose tolerance tests were performed after an overnight fast. Venous blood was taken for blood sugar and insulin estimations were made at $0,15,30,60,90$, and 120 minutes. The results were compared with those from 12 age-matched controls who were all within $10 \%$ of ideal body weight.

In seven coeliac patients and seven control patients an intravenous glucose tolerance test was also performed. Venous blood was removed while the patients were fasting and at 10, 20, 30, 40,50 , and 60 minutes after $25 \mathrm{~g}$ intravenous glucose.

\section{A L A C T ASIA}

Four patients (all male) with a mean age of 35 years were studied. The diagnosis of alactasia had been made on a history of milk intolerance, confirmed by lactose tolerance tests and jejunal lactase activity of under 0.3 units/g mucosa (lower limit of normal lactase activity for our laboratory $1.0 \mathrm{unit} / \mathrm{g}$ mucosa) (Ferguson and Maxwell, 1967). In each case small-bowel histology was normal. In these patients venous blood was taken at 0,15 , $30,60,90$, and 120 minutes after $100 \mathrm{~g}$ oral lactose and results were compared with four age-matched normal control subjects. None of the patients nor control subjects studied were diabetic.

Blood sugar was measured as total reducing substances on a Technicon AutoAnalyzer. Plasma insulin was assayed by the immunoprecipitation technique of Hales and Randle (1963), using standards and antisera previously described (Buchanan and McKiddie, 1967a).

\section{Results}

INSULIN RESPONSE TO GLUCOSE

The effect of intravenous glucose is shown in Fig. 1, and demonstrates a virtually identical sugar and plasma insulin response in control and coeliac groups. There is thus no evidence for a delayed or impaired pancreatic response to the stimulus of hyperglycaemia in the coeliacs.

In control subjects the sugar and insulin curves following oral glucose closely parallel each other (Fig. 2). In the coeliac patients the sugar curve is much flatter (mean maximal rise of only 11 $\mathrm{mg} \%$ ) consistent with glucose malabsorption, the insulin rise is slower than in the controls, with a delayed peak, and the curve does not parallel the sugar curve. Coeliac patients were found to have a significantly lower sugar level at 15 minutes and 30 minutes after oral glucose than controls $(\mathrm{P}<0 \cdot 01)$, but a statistically signi-

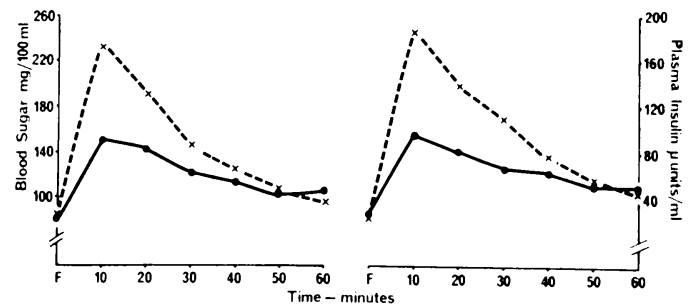

Fig. 1 Sugar and insulin response to intravenous glucose (25g) in seven control subjects (left) and seven coeliac patients (right). (Here and in Figures 2 and 4, - denotes plasma insulin and $\times$ - . $\times$ blood sugar.)

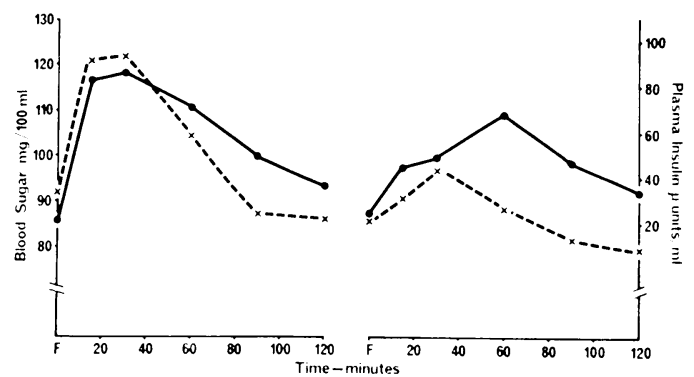

Fig. 2 Sugar and insulin response to oral glucose (50g) in 12 control subjects (left) and 12 coeliac patients (right).

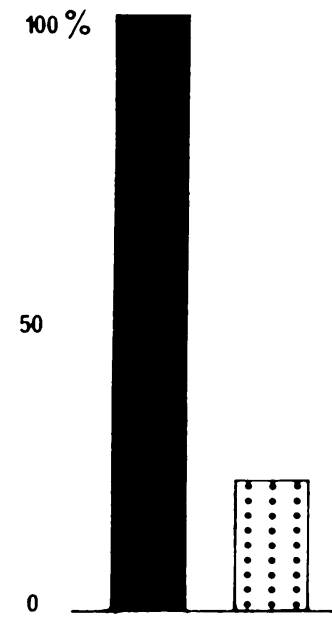

Sugar

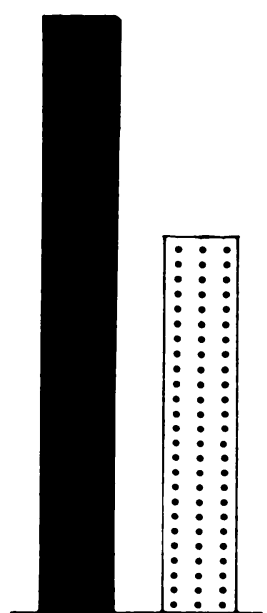

Insulin
Fig. 3 Sugar and insulin areas after oral glucose in control subjects (black area) and coeliac patients (dotted area). 


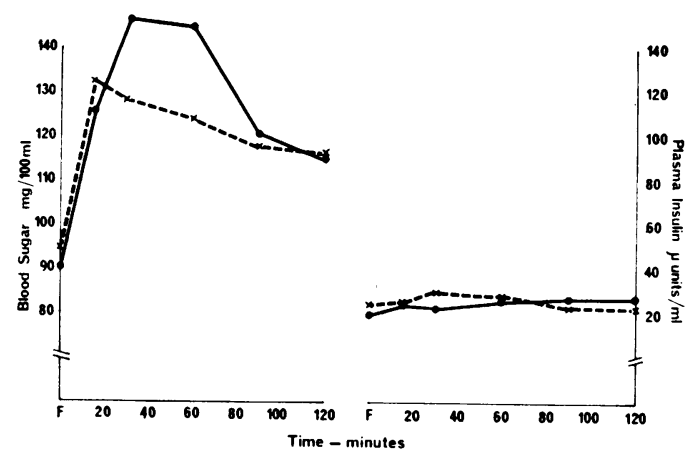

Fig. 4 Sugar and insulin response to oral lactose $(100 \mathrm{~g})$ in control subjects (left) and patients with alactasia (right).

ficant difference in insulin levels occurred only at 15 minutes following oral glucose $(\mathrm{P}<0.05)$.

The areas below the sugar and plasma insulin response curves (calculated as $\mathrm{mg} / \mathrm{min} / 100 \mathrm{ml}$ for sugar and microunits $/ \mathrm{min} / \mathrm{ml}$ for insulin) give some measure of sugar absorption and plasma insulin secretion (Kalkhoff, Schalch, Walker, Beck, Kipnis, and Daughaday, 1964; Perley and Kipnis, 1965). The sugar and insulin areas expressed as percentages of control values are shown in Figure 3. It can be seen that although the overall insulin response in coeliacs is decreased to $65 \%$ of the control value, this is out of proportion to the sugar response which is only $22 \%$ of the response in control patients.

A significant positive correlation was found between sugar and insulin values in control subjects at 60 minutes $(r=0.67), 90$ minutes $(\mathrm{r}=0.70)$, and 120 minutes $(r=0.83)$ after oral glucose. In the coeliac patients on the other hand, where little rise in blood sugar occurs, no correlation was found between sugar and insulin levels at any time during the test period.

\section{INSULIN RESPONSE TO LACTOSE}

Figure 4 shows the effect of oral lactose on the sugar and insulin response in patients with alactasia, and in the control group. In the alactasia group the sugar curve is flat (lactose malabsorption) and there was no insulin response, while in controls there is a normal rise in sugar and insulin levels after oral lactose.

\section{Discussion}

A positive correlation between sugar and insulin levels has been found in the latter part of the oral glucose tolerance test in normal control subjects in this and other studies (Buchanan and McKiddie, 1967b; Martin, Pearson, and Stocks, 1968). These findings are consistent with the view that insulin secretion at this stage is determined by a direct effect of the elevated blood sugar on islet cells, as has been shown with isolated pancreas preparations (Malaisse et al, 1967). On the other hand the absence of correlation between these variables in the first hour after glucose ingestion suggests that insulin secretion during the initial period of the glucose test may be largely the result of a factor or factors other than the blood sugar level, and an insulin release mechanism mediated by the gut may provide the explanation for this early insulin response.

In coeliac patients where glucose absorption is greatly diminished (Holdsworth and Dawson, 1965 ) and the increment in blood sugar above fasting levels is small, no correlation is found at any stage in the test between sugar and insulin values. It is interesting to speculate whether the insulinotropic effect of the bowel might be the major factor in determining insulin secretion throughout the test period in these patients with glucose malabsorption.

These studies provide further evidence for the existence of an insulin-releasing effect by the alimentary tract. The site of release of the insulinstimulating factor remains unknown, but it is unlikely to originate from the liver or portal circulation (McIntyre, Turner, and Holdsworth, 1968; Holdsworth, 1969).

We have shown that the stimulus to the release of an insulinotropic factor does not depend merely on mucosal contact or indirect changes (such as in $p \mathrm{H}$, motility, or osmotic pressure) evoked by the passage of carbohydrate into the lumen of the small bowel, for the presence of unabsorbed lactose in the gut of lactase-deficient patients did not produce a rise in plasma insulin. This suggests that it may be the onset of monosaccharide absorption which stimulates the bowelmediated release of insulin after oral carbohydrate. As there is experimental evidence that insulin can enhance the absorption of glucose from the small intestine in vitro (Love and Canavan, 1968) such an interrelationship could provide a feedback system for facilitating glucose absorption.

We thank Professor E. M. McGirr and Dr A. H. Imrie for their encouragement and support, and are grateful for Miss Isobel Hunter's expert technical assistance. One of us, J.D.M., was in receipt of a McIntyre research scholarship from the Royal Infirmary, Glasgow.

\section{References}

Buchanan, K. D., and McKiddie, M. T. (1967a). Experience with the immunoprecipitation technique of insulin assay with reference to sensitivity, precision and specificity. Clin. chim. Acta, 15, 315-320.

Buchanan, K. D., and McKiddie, M. T. (1967b). The normal insulin response to glucose. The relationship between blood sugar and plasma insulin. Diabetologia, 3, 460-464. 
Ferguson, A., and Maxwell, J. D. (1967). Genetic aetiology of lactose intolerance. Lancet, 2, 188-190.

Field, J. B. (1964). Factors concerned with insulin synthesis and release. Metabolism, 13, 407-421.

Hales, C. N., and Randle, P. J. (1963). Immunoassay of insulin with insulin-antibody precipitate. Biochem $J ., 88,137-146$.

Holdsworth, C. D. (1969). The gut and oral glucose tolerance. Gut, 10, 422-427.

Holdsworth, C. D., and Dawson, A. M. (1965). Glucose and fructose absorption in idiopathic steatorrhoea. Gut, 6 , 387-391.

Kalkhoff, R., Schalch, D. S., Walker, J. L., Beck, P., Kipnis, D. M., and Daughaday, W. H. (1964). Diabetogenic factors associated with pregnancy. Trans. Ass. Amer. Phycns., 77, 270-280.

Lancet (1966). Intestinal hormones and insulin. (Leading article). Lancet, $2,35$.

Love, A. H. G., and Canavan, D. A. (1968). Effects of insulin on intestinal glucose absorption. Lancet, 2, 1325-1326.
McIntyre, N., Holdsworth, C. D., and Turner, D. S. (1964). New interpretation of oral glucose tolerance. Lancet, 2, 20-21.

McIntyre, N., Turner, D., and Holdsworth, D. (1968). Liver and oral carbohydrate tolerance, Gut, 9, 730.

Malaisse, W., Malaisse-Lagae, F., and Wright, P. H. (1967). A new method for the measurement in vitro of pancreatic insulin secretion. Endocrinology, 80, 99-108.

Martin, F. I. R., Pearson, M. J., and Stocks, A. E. (1968). Glucose tolerance and insulin insensitivity. Lancet, 1, 1285-1286

Mayhew, D. A., Wright, P. H., and Ashmore, J. (1969). Regulation of insulin secretion. Pharmacol. Rev., 21, 183-212.

Perley, M., and Kipnis, D. M. (1965). Differential plasma insulin responses to oral and infused glucose in normal weight and obese non-diabetic and diabetic subjects. J. Lab. clin. Med., 66, 1009.

Yalow R. S., and Berson, S. A. (1960). Immunoassay of endogenous plasma insulin in man. J. clin. Invest., 39, 1157-1175. 